\title{
Stent-graft repair for aortic type B dissections with insidious renal malperfusion
}

\author{
Bertrand De Latour, MD, ${ }^{a}$ Regis Delaunay, MD, ${ }^{\mathrm{b}}$ Joseph Rivalan, MD, ${ }^{\mathrm{c}}$ Jean-François Heautot, MD, PhD, ${ }^{\mathrm{d}}$ and \\ Jean-Philippe Verhoye, MD, PhD ${ }^{\mathrm{a}}$ Rennes, France
}

$\mathrm{W}$ e report 2 cases of complicated type B aortic dissection, presenting clinically silent renal malperfusion with a nonenhancing right kidney and contralateral renal hypertrophy. After endovascular treatment, the reperfused kidney regained normal size and function and the hypertrophic contralateral kidney returned to a normal size.

\section{Clinical Summaries}

PATIENT 1. A 44-year old man was admitted for acute lower limb ischemia as previously reported. ${ }^{1}$ A perioperative angiogram revealed a dissected appearance of the left common iliac artery. Perfusion was restored by stenting into the true lumen of the common iliac artery. A computed tomographic (CT) scan demonstrated complete type B aortic dissection. The celiac, superior mesenteric, and right renal arteries were malperfused because of dynamic compression of the true lumen by the false lumen. The right kidney was atrophic (95-mm long axis) and nonfunctioning on scintigraphy. The left kidney showed compensatory hypertrophy (142-mm long axis) (Figure 1, A). The patient had recent hypertension but had refused to comply with the recommended management of this hypertension.

One week after his admission, the patient had signs of acute mesenteric ischemia. A stent graft was deployed in the thoracic aorta to cover the primary intimal tear, redirecting flow into the true lumen and effectively decompressing the false lumen.

The signs of mesenteric ischemia gradually resolved. A discharge CT angiographic scan showed successfully restored flow into the enlargement of the true lumen. The patient was discharged symptom-free on the 19th day with a systolic blood pressure of $120 \mathrm{~mm} \mathrm{Hg}$ obtained by 4-agent oral therapy. Duplex ultrasound showed satisfactory blood flow in the mesenteric, renal, and lower limb arteries. CT follow-up at 6 months showed a right kidney measuring $113 \mathrm{~mm}$ and a left

\footnotetext{
From the Departments of Thoracic, Cardiac and Vascular Surgery, ${ }^{\mathrm{a}}$ Cardiology, ${ }^{\mathrm{b}}$ Nephrology, ${ }^{\mathrm{c}}$ and Radiology and Medical Imaging, ${ }^{\mathrm{d}}$ University Hospital Pontchaillou, Rennes, France.

Received for publication May 22, 2007; accepted for publication May 30, 2007.

Address for reprints: Jean Philippe Verhoye, MD, PhD, Department of Cardiac, Thoracic and Vascular Surgery, University Hospital Pontchaillou, Rue Henri Le Guillou, 35000 Rennes, France (E-mail: jean-philippe. verhoye@ chu-rennes.fr).

J Thorac Cardiovasc Surg 2007;134:1342-3

$0022-5223 / \$ 32.00$

Copyright $\odot 2007$ by The American Association for Thoracic Surgery doi:10.1016/j.jtcvs.2007.05.064
}

kidney measuring $128 \mathrm{~mm}$ (Figure 1, B). Scintigraphy showed complete functional recovery of the right kidney with symmetrical uptake of the tracer. Systolic blood pressure is still currently $120 \mathrm{~mm} \mathrm{Hg}$ with a 2-agent regimen of therapy (betablocker and angiotensin-converting enzyme inhibitor).

PATIENT 2. A 54-year-old man was initially referred for uncomplicated type B aortic dissection. A CT angiogram showed the right renal artery arising from the true lumen and the left from the false lumen. Both kidneys were normal in size $(11 \mathrm{~cm})$. Despite an image of a collapsed true lumen, duplex ultrasound showed symmetric perfusion. Renal function was within normal limits (creatinine level $104 \mu \mathrm{mol} / \mathrm{L}$ ). Blood pressure remained difficult to control with a 5 -agent regimen of therapy.

During the following days, because of worsening renal function $(150 \mu \mathrm{mol} / \mathrm{L})$, a new $\mathrm{CT}$ angiogram and duplex ultrasound were performed. These studies showed a normally perfused left kidney of $12 \mathrm{~cm}$, whereas the right kidney was malperfused and measured $9 \mathrm{~cm}$, showing ischemic atrophy by true lumen compression (dynamic ischemia) (Figure 1, C). Scintigraphy showed a nonfunctioning right kidney and functionally single left kidney. Global glomerular filtration rate was $74 \mathrm{~mL} / \mathrm{min}$.

In view of the dynamic right kidney ischemia and refractory hypertension, a stent graft was deployed to occlude the primary intimal main entry tear. Collapse of the true lumen was reversed, with restoration of flow into the right kidney.

Discharge duplex ultrasound and a CT angiogram showed normal perfusion and symmetric size $(11 \mathrm{~cm})$ of both kidneys (Figure 1,D).

The CT angiogram at 1 year's follow-up was similar to the discharge angiogram. Scintigraphy showed recovery of right kidney uptake (60\% right vs $70 \%$ left, $65 \%$ total) and symmetric perfusion with a global glomerular filtration rate of $110 \mathrm{~mL} / \mathrm{min}$ (left and right side, 55\% each). Systolic blood pressure was 125 $\mathrm{mm} \mathrm{Hg}$ with a 2-agent therapy regimen (beta blocker and angiotensin-converting enzyme inhibitor).

\section{Discussion}

Silent type B aortic dissections raise a risk of renal malperfusion. The clinical cases reported here represent examples of renovascular malperfusion with an insidious onset. With the first case, the intestinal menace was the chief reason for stentgraft insertion. Recovery of malperfused kidney trophicity observed on the follow-up CT was surprising. Known predicting factors of a good result of revascularization are a glomerular blood pressure greater than $30 \mathrm{~mm} \mathrm{Hg},{ }^{2}$ a peripheral resistance index less than $0.80,{ }^{3}$ and a kidney size greater than $9 \mathrm{~cm} .{ }^{4}$ This case presented all of the required conditions to allow "hiberna- 




Figure 1. A, Patient 1. CT scan showing compensatory hypertrophy of the left kidney. B, CT scan of the kidneys at 6 months' follow-up. C, Patient 2. Study shows normally perfused left kidney and malperfused right kidney. D, Study on discharge shows normal perfusion and symmetric size $(11 \mathrm{~cm})$ of both kidneys.

tion" of the malperfused kidney with recovery after restoration of effective reperfusion. The regression of the compensatory hypertrophy of the contralateral kidney was noteworthy.

This experience led us to treat the second patient as soon as early signs of renal atrophy appeared, with an equally good result.

Renal malperfusion in aortic dissection is often overlooked owing to the minimal clinical features. Systematic screening for renal malperfusion, associated with the good results of endovascular techniques, can prevent renal atrophy that is still too frequently discovered at a late stage.

\section{References}

1. Verhoye J-P, De Latour B, Heautot J-F. Return of renal function after endovascular treatment of aortic dissection. $N$ Engl J Med. 2005;352:1824-5.

2. Mesnard L, Delahousse M, Raynaud A, de Tovar G, Pastural M, Chaignon M, et al. Delayed angioplasty after renal thrombosis. Am J Kidney Dis. 2003;41:E9-12.

3. Radermacher J, Chavan A, Bleck J, Vitzthum A, Stoess B, Gebel MJ, et al. Use of Doppler ultrasonography to predict the outcome of therapy for renal-artery stenosis. $N$ Engl J Med. 2001;344:410-7.

4. Soulez G, Therasse E, Qanadli SD, Froment D, Léveillé M, Nicolet V, et al. Prediction of clinical response after renal angioplasty: respective value of renal Doppler sonography and scintigraphy. AJR Am J Roentgenol. 2003;181:1029-35. 